\title{
Acceptability of baseball face guards and reduction of oculofacial injury in receptive youth league players
}

Ronald P Danis, Kuolung Hu, Mason Bell

\begin{abstract}
Goals-To assess the relative injury reduction effect and acceptability of face guards on batter's helmets.

Methods-A non-randomized prospective cohort study among 238 youth league baseball teams in Central and Southern Indiana during the 1997 season. Coaches, parents, and players were asked to respond to pre-season and post-season questionnaires. Approximately one half of the teams were supplied with face guard helmets (intervention); all others used this protection at their discretion (comparison).

Results-Parents, players, and coaches on the intervention teams reported a reduction in the incidence of oculofacial injuries compared with comparison team respondents $(p=0.04)$. There was no reported adverse effect of face guard use on player performance.

Conclusions-Helmet face guards should be required for batters to prevent facial injuries in baseball.

(Injury Prevention 2000;6:232-234)
\end{abstract}

Keywords: oculofacial injury; dental injury; ocular trauma; baseball

Prevent Blindness Indiana, Indianapolis M Bell

Correspondence and reprint requests to: Dr Danis,

Director, Eye Injury Registry

of Indiana (email:

rdanis@iupui.edu)

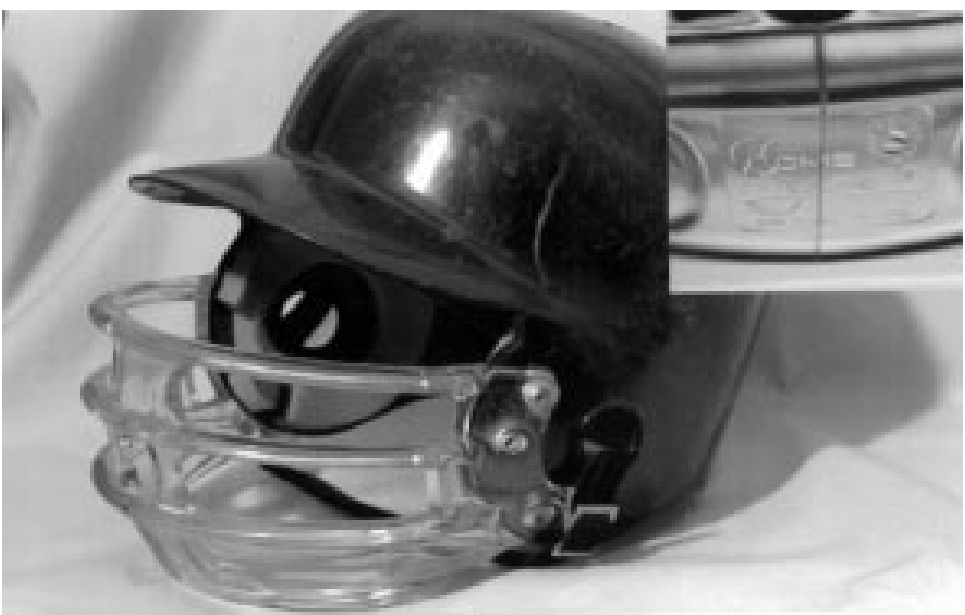

Figure 1 A baseball face guard consisting of a polycarbonate arch affixed to the ear flaps of a standard batter's helmet. Inset: close up photograph of a fracture in the arch caused by a pitched ball impact while worn by an 8 year old face guard team batter. This product was manufactured to the specifications of ASTM F910, which prevents facial contact from a baseball fired at 69 miles per hour. ${ }^{10} 11$ sports related facial injuries requiring medical attention in the US ${ }^{2}$ and for most severe ocular injuries. ${ }^{1-6}$ In addition, baseball is a leading cause of dental injury ${ }^{2}$ and maxillofacial fractures $^{7-9}$ among child players.

In response to high rates of oculofacial injury in other sports, such as ice hockey, American football, and cricket, helmets have been modified to provide facial protection. Face guards that affix to the ear flaps on the standard baseball batter's helmet are commercially available (fig 1) and are endorsed by the US Consumer Products Safety Commission. Unfortunately, this equipment is rarely employed at present. ${ }^{1}$

The goals of this study were to (1) to evaluate the preventive effect of face guard use and (2) to determine their acceptability.

\section{Methods}

A non-randomized prospective cohort study compared two groups of youth league players in Indiana during the 1997 season. One group agreed to have all players at bat or when base running wear the face guard for the entire season. This group was given four or five of these helmets (intervention group, $\mathrm{n}=136$ teams). A second group used face guards on an individual, voluntary basis (comparison group, $\mathrm{n}=102$ teams). The team assignments were made in this manner because league administrators refused to cooperate with the proposed randomization design.

Face guards were either a polycarbonate variety attaching to the ear flaps of the batting helmet with a 2 inch $(5 \mathrm{~cm})$ opening between the visor of the helmet and the superior part of the arch (102 teams) (Home-Safe; Salem, VA; fig 1) or a wire mesh variety of similar configuration (34 teams) (Rawlings; St Louis, MO).

Players, coaches, and parents were surveyed by questionnaires at the beginning and end of the season as to face guard use relative to past and current season injuries by a bat or ball.

\section{Results}

The two groups were similar with respect to the age of players. No other comparisons were made but it is assumed that they were also similar with respect to other factors likely to affect the risk of injury.

\section{PRE-SEASON RESPONSES}

Coaches

In prior seasons, $49.2 \%$ had coached a child who was hit in the face but there was no significant difference in such hits between 
intervention $(n=163)$ and comparison team coaches $(n=164)$. However, intervention coaches more often agreed that facial impacts were significant sources of injury $(48.5 \% v$ $31.7 \%, p=0.002$, Fisher's exact test) and that face guard use should be mandated $(46.0 \% v$ $21.9 \%, \mathrm{p}=0.013)$.

Players

Before the study period $26.4 \%$ of players $(n=2294)$ reported that they had been struck in the face while playing baseball, $18.0 \%$ agreed that the ball sometimes scared them, and $62.5 \%$ thought they would wear a face guard if it were made available. There were no significant differences between intervention $(n=1421)$ and comparison team $(n=873)$ participants responses to these questions.

\section{Parents}

Pre-season, $27.4 \%$ of parents $(n=2240)$ reported their child had been struck while playing baseball, $22.2 \%$ said they had never heard of face guards, and $40.3 \%$ had never seen one. None the less, $57.6 \%$ said they would be willing to purchase a face guard for their child. Again, none of these differences were statistically significant.

\section{POST-SEASON RESPONSES}

Coaches

Intervention team coaches reported a $28.0 \%$ lower incidence of facial impacts/injuries than comparison team coaches $(12.3 \% v 15.7 \%)$. There were also 22 reports by intervention coaches of a potential injury after face guard impacts with ball or bat versus six such reports in comparison teams. The proportion of intervention team coaches who agreed that face guard use should be mandatory increased from $46.0 \%$ to $70.5 \%(\mathrm{p}<0.001)$.

Players

A facial injury reported by a player was included in the analysis if sufficient descriptive details were given or if a parent or coach corroborated the report. Using these criteria, the incidence of facial impacts/injuries was $28.0 \%$ less in the intervention group (40 of $743 ; 5.3 \%$ ) of players on comparison than on intervention teams (50 of $1205 ; 4.1 \%$ ).

Post-season questionnaires showed that $94.8 \%$ of intervention and $8.3 \%$ of comparison team players used the face guard. The majority $(81.2 \%)$ thought that it was "OK" to wear, $27.8 \%$ thought they played better using it, and $41.5 \%$ said they were less afraid of the ball. Complaints about the face guard included $12.1 \%$ who thought they played worse with it, discomfort $(23.3 \%)$, and vision obstruction $(40.3 \%)$.

\section{Parents}

Twenty seven of $988(3.6 \%)$ parents of comparison team players versus 24 of 1214 $(1.9 \%)$ parents of intervention team players reported a facial impact injury $(\mathrm{p}=0.04$, one tailed $\left.\chi^{2}\right)$. Ten players reportedly saw a physician due to the injury, eight of whom were on comparison teams.
Most parents (91.5\%) of children on intervention teams thought their child accepted the face guard; $84.7 \%$ wanted their child to use one next season compared with $53.9 \%$ of control team parents.

\section{Discussion}

The reduction in facial injuries among the intervention team players in this study is consistent with a relative injury prevention effect of the face guard to batters and base runners. The batter is the player position most vulnerable to facial injury because of proximity to the batted and pitched ball. ${ }^{136{ }^{12-14}}$ Unfortunately, because the injuries were not verified by medical examination, and the precise position of injured players was not always documented, the findings are not conclusive.

\section{LIMITATIONS}

Coaches of teams using face guards were more likely to favor their use at the beginning of the season. This selection bias may be reflected in a coach's attitude, which may, in turn, have an effect on players and parents attitudes. Nevertheless, it appears that if presented in a positive light, parents and players in this sample are prepared to accept face guards as routine safety equipment.

The perceived positive effect on player performance reported by the intervention group respondents tends to support the apparent acceptability of this protective measure. This view, again, must be considered in light of the bias of some coaches.

\section{Implications for prevention}

This study implicates another sport, alongside youth ice hockey, American football, and racquet sports, that engenders a significant risk of oculofacial injury. In spite of its availability and apparent acceptability, however, the requisite safety equipment is rarely employed. To foster this measure, it is necessary to further educate coaches regarding the benefits of protective equipment. In addition, league administrators, parents, and coaches should consider mandating these face guards. They are a simple modification of the batter's helmet that is already widely used in youth leagues.

Supported by a grant from the Midwest Eye Foundation, Inc, Indianapolis, to Prevent Blindness Indiana, Inc, Indianapolis, and in part by an unrestricted grant from Research to Prevent Blindness, New York.

1 Kyle S. Youth baseball protective equipment project final report. Washington, DC: US Consumer Products Safety Commission, 1996.

2 Rutherford G, Miles R, Brown V, et al. Overview of sports-related injuries to persons 5-14 years of age. Washington, DC: US Consumer Products Safety Commission, 1981 .

3 Nelson L, Wilson T, Jeffers J. Eye injuries in childhood: demography, etiology, and prevention. Pediatrics 1989;84: $438-41$

4 Larrison W, Hersh P, Kunzweiler T, et al. Sports-related ocular trauma. Ophthalmology 1990;97:1265-9.

5 Schein $\mathrm{O}$, Hibberd P, Shingleton B, et al. The spectrum and burden of ocular injury. Ophthalmology 1988;95:300-5.

6 Grin T, Nelson L, Jeffers JB. Eye injuries in childhood. Pediatrics 1987;80:13-17.

7 Castaldi C. Sports-related oral and facial injuries in the young athlete:a new challenge for the pediatric dentist. Pediatr Dent 1986;8:311-16. 
8 Crow R. Diagnosis and management of sports-related injuries to the face. Dent Clin North Am 1991;35:719-32.

Tanaka N, Hayashi S, Amagasa T, et al. Maxillofacial fractures sustained during sports. F Oral Maxillofac Surg 1996;54:715-19

10 American Society for Testing and Materials. Standard specifications for eye protectors for use by players of selected sports. West Conshoshoken, PA: ASTM, 1998

11 National Operating Committee on Standards for Athletic Equipment. Standard method of impact test and performance requirements for baseball/softball batter's helmets. Rhode Island: NOCSAE, 1991.

12 Pasternack J, Veenema K, Callahan C. Baseball injuries: a Little League series. Pediatrics 1996;98:445-8.

13 Hale C. Protective equipment for baseball. Phys Sports Med 1979;7:59-63.

14 Kuhn F, Witherspoon C, Morris R. Baseball-related eye injuries. In: Andrews J, Zarins B, Wilk K, eds. Injuries in baseball. Philadelphia: Lippincott-Raven, 1998: 395-400.

\section{Editorial board member: brief biography}

SUSAN P BAKER MPH, SCD (HON)

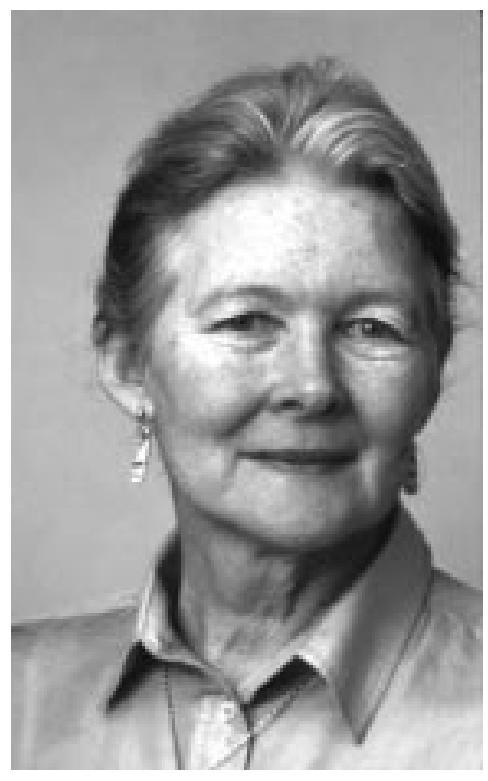

Susan Baker, one of the journal's Honorary Editors, is Professor and Associate Chair of the Department of Health Policy and Management at the Johns Hopkins School of Public Health, where she has a joint appointment in Environmental Health Sciences. She also holds joint appointments in the School of Medicine in the Pediatrics and Emergency Medicine departments.

An epidemiologist specialising in injury prevention, Professor Baker was the first Director of the Johns Hopkins Injury Prevention Center. She has served as vice chair of the National Academy of Science's Committee on Trauma Research and as President of the American Association for Automotive Medicine. Her research topics have included injuries related to motor vehicles and airplane crashes as well as medical care of the injured, injury severity scoring, geographic variation in injury mortality, and deaths and injuries in the military population, to name but a few. She is well known for developing the widely used injury severity score. Her long list of publications include eight textbook chapters, more than 200 journal articles, magazine articles for the public, and three books-The Injury Fact Book, Saving Children: A Guide to Injury Prevention, and Injury Prevention: an International Perspective.

Sue Baker's talents extend beyond the academic. She has taken primary and advanced courses in airplane crash survival investigation and has served on FAA sponsored expert panels on shoulder restraint use and the Age 60 Rule. She is a member of the Armed Forces Epidemiological Board. She is a also licensed private pilot and an Associate Fellow of the Aerospace Medical Association.

She has been awarded the Prince Bernhard Medal for distinguished research, the Association for the Advancement of Automotive Medicine's Award of Merit, the American Trauma Society's Distinguished Achievement Award and Stone Lectureship Award-and being named "Bad Guy of the Month" by Road Rider motorcyclist magazine! In 1989, Professor Baker received the prestigious Charles A Dana Award for Pioneering Achievements in Health. A distinguished speaker, the American Association for the Surgery of Trauma, of which she is an honorary member, chose her to give the Fitz Oration in 1996. Johns Hopkins University presented her with the Distinguished Alumnus Award in 1996, and two years later the University of North Carolina, Chapel Hill, bestowed on her an honorary Doctor of Science degree. In 1999, the American Public Health Association gave her its Award for Excellence.

Susan Baker is, in her own words, an ardent advocate for policy changes that will prevent injuries. Much of her teaching and research has been-and continues to be-designed to influence the legislators, administrators, media representatives, and others whose decisions can determine the likelihood of injury for thousands of people. 